Tropical Journal of Pharmaceutical Research July 2020; 19 (7): 1383-1388

ISSN: $1596-5996$ (print); 1596-9827 (electronic)

(C) Pharmacotherapy Group, Faculty of Pharmacy, University of Benin, Benin City, 300001 Nigeria.

Available online at http://www.tjpr.org

Original Research Article

http://dx.doi.org/10.4314/tjpr.v19i7.7

\title{
Baicalein inhibits cell development in papillary thyroid cancer by regulating miR-206/RAP1B pathway
}

\author{
Peng Wang, Liang Guo, Zhong Liang, Jianlin Lou, Jianqiang Zhao* \\ Department of Head and Neck Surgery, Institute of Cancer Research and Basic Medical Sciences of Chinese Academy of \\ Sciences, Cancer Hospital of University of Chinese Academy of Sciences, Zhejiang Cancer Hospital, Hangzhou City, Zhejiang \\ Province 310022, China
}

*For correspondence: Email: EDFO90vb@163.com; Tel: +86-571-88128222

Sent for review: 7 May 2020

Revised accepted: 30 June 2020

\begin{abstract}
Purpose: To investigate the therapeutic effect of baicalein on papillary thyroid cancer (PTC) cells in vitro and its underlying molecular mechanism.

Methods: The human PTC cell line TPC-1 was divided into five groups and treated with distilled water or baicalein at 10, 20, 50, or $100 \mu \mathrm{M}$. Next, miR-206, miR-206 inhibitor, the respective negative controls of miR-206 and miR-206 inhibitor, RAP1B small interfering RNA (siRNA), and control vector siRNA were synthesized and transfected into TPC-1 cells. Cell viability, migration, and invasion were measured using the 3-(4,5-dimethyl-2-thiazolyl)-2,5-diphenyl-2-H-tetrazolium bromide (MTT) and Transwell assays. miR-206 expression and Ras-related protein (RAP1B) levels were assessed by quantitative real-time reverse transcription-polymerase chain reaction and western blotting, respectively. Results: Baicalein inhibited TPC-1 cell viability, migration and invasion, upregulated miR-206 expression, and reduced the RAP1B level in a concentration-dependent manner $(p<0.01)$. miR-206 negatively regulated $R A P 1 B$ expression and increased the baicalein-induced reduction of RAP1B expression. Moreover, RAP1B overexpression relieved the suppression of cell viability, migration, and invasion caused by baicalein $(p<0.01)$.

Conclusion: Baicalein suppresses cell growth in PTC cells by regulating the miR-206/RAP1B pathway, providing a new therapeutic strategy for PTC treatment.
\end{abstract}

Keywords: Baicalein, Papillary thyroid cancer (PTC), miR-206, RAP1B, Cell viability, Cell invasion

\begin{abstract}
This is an Open Access article that uses a fund-ing model which does not charge readers or their institutions for access and distributed under the terms of the Creative Commons Attribution License (http://creativecommons.org/licenses/by/4.0) and the Budapest Open Access Initiative (http://www.budapestopenaccessinitiative.org/read), which permit unrestricted use, distribution, and reproduction in any medium, provided the original work is properly credited.

Tropical Journal of Pharmaceutical Research is indexed by Science Citation Index (SciSearch), Scopus, International Pharmaceutical Abstract, Chemical Abstracts, Embase, Index Copernicus, EBSCO, African Index Medicus, JournalSeek, Journal Citation Reports/Science Edition, Directory of Open Access Journals (DOAJ), African Journal Online, Bioline International, Open-J-Gate and Pharmacy Abstracts
\end{abstract}

\section{INTRODUCTION}

Thyroid cancer is a malignant tumor that originates in the follicular epithelium of the thyroid, and it usually presents as a painless neck mass or nodule [1]. Based on differences in tumor origin and differentiation, thyroid cancer can be classified as papillary thyroid cancer (PTC), follicular thyroid cancer (FTC), medullary thyroid carcinoma (MTC), and anaplastic thyroid carcinoma (ATC) [2]. PTC is the most common type of thyroid cancer with slow growth, low malignancy, and a good prognosis [3]. PTC is mainly treated by surgery, supplemented with endocrine therapy and molecular-targeted therapy. However, the treatment time of PTC is longer, and the drugs taken by patients have more side effects, including hyperthyroidism [3]. 
Therefore, identifying a natural drug substitute for PTC is very important.

Baicalein (also known as 5, 6, 7trihydroxyflavone) is a flavonoid compound extracted from the dried roots of Scutellaria baicalensis [4]. Baicalein has multiple pharmacological effects, such as antibacterial, anti-inflammatory, anti-infection, and antioxidation effects $[5,6]$. In addition, baicalein has anti-cancer effects. For example, baicalein inhibits the growth, metastasis, and invasion of prostate cancer and gastric cancer cells $[6,7]$. Baicalein also regulates the mitogen-activated protein kinase (MAPK) pathway to induce apoptosis in ATC cells [8]. Therefore, baicalein may be an ideal therapeutic compound for thyroid cancer.

MicroRNAs (miRNAs) are closely related to tumor development [9]. Studies have found that multiple miRNAs are linked to the occurrence, development, and prognosis of PTC. For example, Chou et al reported that the expression levels of miR-146b, miR-221, and miR-222 are correlated with extra-glandular invasion and tumor stage of PTC [10].

The earliest study on miR-206 is related to breast cancer [11]. Since then, miR-206 has been gradually found to affect apoptosis and metastasis in various tumor cells. For example, miR-206 promotes apoptosis in cervical cancer cells by targeting the NOTCH3 signaling pathway [11]. Additionally, miR-206 inhibits thyroid cancer proliferation and invasion by targeting Rasrelated protein (RAP1B) [12].

This study systematically investigated the therapeutic effect of baicalein on the PTC cell line TPC-1 and its molecular mechanism in vitro and provides a new strategy for PTC treatment.

\section{EXPERIMENTAL}

\section{Cell culture and treatment}

The human PTC cell line TPC-1 was cultured in Roswell Park Memorial Institute (RPMI)-1640 medium (Procell, Wuhan, China) with $10 \%$ fetal bovine serum (FBS) and $1 \%$ penicillinstreptomycin solution (Procell) in an incubator with $95 \%$ air and $5 \% \mathrm{CO}_{2}$ at $37^{\circ} \mathrm{C}$.

The cultured cells were divided into five groups. The cells in one group were treated with distilled water (control or $0 \mu \mathrm{M}$ baicalein group), and the cells in the other four groups were treated with $10,20,50$, or $100 \mu \mathrm{M}$ baicalein (Abmole Bioscience Inc, Houston, TX, USA) for $72 \mathrm{~h}$.

\section{Cell viability assay}

TPC-1 cells in the $50-\mu \mathrm{M}$ baicalein group were seeded into 96-well plates at a density of $2 \times 10^{3}$ cells/well and were cultured for 3 days. Next, 20 $\mu \mathrm{L}$ of 3-(4,5-dimethyl-2-thiazolyl)-2,5-diphenyl-2$\mathrm{H}$-tetrazolium bromide (MTT, $5 \mathrm{mg} / \mathrm{mL}$ in phosphate-buffered saline solution) purchased from Beyotime (Shanghai, China) was added directly to each well. The cells were incubated for $2 \mathrm{~h}$ at $37{ }^{\circ} \mathrm{C}$ and then were added to $5 \mathrm{~mL}$ of acidified isopropanol (Sigma-Aldrich, St. Louis, $\mathrm{MO}$, USA). The absorbance of the cell suspension at $570 \mathrm{~nm}\left(\mathrm{OD}_{570}\right)$ was measured using a spectrophotometer (Lab-Spectrum Instruments Co. Ltd, Shanghai, China).

\section{Cell migration and invasion assays}

The TPC- 1 cells treated with $50 \mu \mathrm{M}$ baicalein were digested with $0.25 \%$ trypsin. The upper membrane of the Transwell chamber was incubated in Matrigel solution (BD Biosciences, San Jose, CA, USA) for $30 \mathrm{~min}$ at $37^{\circ} \mathrm{C}$ and then was co-incubated with digested TPC-1 cells for $24 \mathrm{~h}$ at $37^{\circ} \mathrm{C}$. At the same time, FBS was added to the lower membrane of the Transwell chamber. The incubated cells were stained with $0.1 \%$ hematoxylin (Sigma-Aldrich) for $30 \mathrm{~min}$. The numbers of migrating and invading cells were counted using a microscope (Leica, Tokyo, Japan) and photographed using a digital camera (Canon, Tokyo, Japan).

\section{Cell transfection}

miR-206, miR-206 inhibitor, the negative controls of miR-206 and miR-206 inhibitor (miR-NC and NC inhibitor, respectively), RAP1B small interfering RNA (siRNA) or control vector siRNA were synthesized by Sangon Biotech Co. Ltd (Shanghai, China). According to the manufacturer's protocol, the cells were transfected using Lipofectamine 3000 (Thermo Fisher Scientific, Waltham, MA, USA) for $24 \mathrm{~h}$ at $37^{\circ} \mathrm{C}$.

\section{Quantitative real-time reverse transcription- polymerase chain reaction (qRT-PCR)}

Total RNA from TPC-1 cells was extracted using the Trizol Extraction Kit (Sigma-Aldrich). The RNA quantity and quality were detected using the NanoDrop 2000c system (Thermo Fisher Scientific. The RNA was reverse transcribed to cDNA using reverse transcriptase. The cycling conditions were as follows: $95^{\circ} \mathrm{C}$ for $1 \mathrm{~min}$, followed by 40 cycles of amplification $\left(94^{\circ} \mathrm{C}\right.$ for $10 \mathrm{~s}, 55^{\circ} \mathrm{C}$ for $40 \mathrm{~s}$, and $72{ }^{\circ} \mathrm{C}$ for $20 \mathrm{~s}$ ), and 72 ${ }^{\circ} \mathrm{C}$ for $8 \mathrm{~min}$. The fold changes were calculated 
using the relative quantification $\left(2^{-\Delta \Delta C t}\right)$ method. The sequences of the PCR primers used are shown in Table 1.

Table 1: Primers and sequences

\begin{tabular}{lll}
\hline Primer & & Sequence (5'-3') \\
\hline miR- & Forwar & UGGAAUGUAAGAAGUGUGU \\
206 & d & GG \\
& Reward & ACACACUUCCUUACAUUCCAU \\
miR- & & \\
206 & Forwar & CCACACACUUCCUUACAUUCC \\
inhibito & d & A \\
$r$ & Reward & CAGUACUUUUGUGUAGUACAA \\
& $\begin{array}{l}\text { Forwar } \\
\text { RAP1B }\end{array}$ & CGTGGCGCCTAGAGTAG \\
& Reward & AGTACCTCTCAGGCTGTCACC \\
\hline
\end{tabular}

\section{Western blotting}

The total protein of TPC-1 cells was extracted by incubating in RIPA lysis buffer containing the protease inhibitor phenylmethylsulfonyl fluoride (PMSF; Beyotime) for 30 min on ice and sampled onto configured gel. Next, the protein extracts were mixed with sodium dodecyl sulfate (SDS) solution (Beyotime), separated by $10 \%$ SDSPAGE and transferred onto polyvinylidene fluoride (PVDF) membranes soaked in methanol. The membranes were blocked in $5 \%$ milk for $1 \mathrm{~h}$ at room temperature, incubated with RAP1B primary antibody (ab154756; 1:1,000; Abcam, Cambridge, UK) and glyceraldehyde-3phosphate dehydrogenase (GAPDH; ab9484; $1: 1,000$; Abcam) at $4^{\circ} \mathrm{C}$ overnight, and then incubated with secondary antibody (anti-mouse IgG antibody; ab6728; 1:2,000) for $1 \mathrm{~h}$ at room temperature. The immunoblots were visualized and analyzed using ImageJ software $(\mathrm{NIH}$ Image, Bethesda, MD, USA).

\section{Statistical analysis}

All the experimental data were compared using Student's $t$-test. The results were statistically analyzed using GraphPad Prism v8 software (Graphpad, San Diego, CA, USA) and were represented as means \pm standard deviation (SD). $P<0.05$ indicated statistical significance.

\section{RESULTS}

Baicalein inhibits TPC-1 cell viability, migration, and invasion

Cell growth was measured to study the therapeutic effect of baicalein on PTC in vitro. The MTT assay showed that cell viability was reduced by baicalein in a concentration- dependent manner in TPC-1 cells (Figure $1 \mathrm{~A} ; p$ $<0.001)$. The Transwell assay showed that the number of migrating or invading cells in the 50$\mu \mathrm{M}$ baicalein group was less than that in the 0 $\mu \mathrm{M}$ baicalein group (Figure $1 \mathrm{~B} ; p<0.001$ ). These data explained that baicalein could suppress PTC cell growth in vitro.
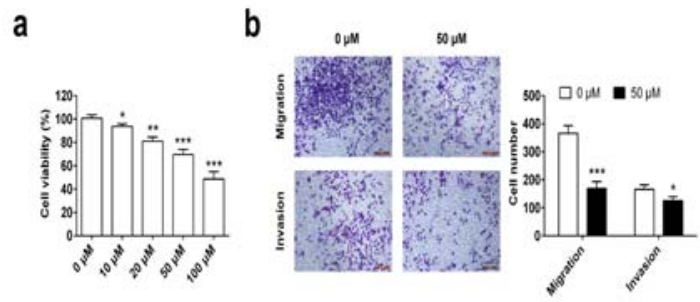

Figure 1: Baicalein inhibits TPC-1 cell viability, migration and invasion. TPC-1 cells were treated with $0,10,20,50$ and $100 \mu \mathrm{M}$ baicalein. (A) Cell viability, (B) migration and invasion were detected using the MTT and Transwell assays. ${ }^{*} p<0.05,{ }^{* *} p<0.01,{ }^{* * *} p$ $<0.001$

\section{Baicalein upregulates RAP1B expression by regulating miR-206 expression}

qRT-PCR showed that the miR-206 expression level was elevated by baicalein in a concentration-dependent manner in TPC-1 cells (Figure $2 \mathrm{~A} ; p<0.01$ ). By contrast, qRT-PCR and western blotting results both showed that RAP1B expression was increased when cells were treated with $10,20,50$, or $100 \mu \mathrm{M}$ baicalein (Figure $2 \mathrm{~B}$ and $\mathrm{C}$, respectively; $p<0.01$ ). The data suggest that baicalein upregulates miR-206 expression and reduces the RAP1B level. a

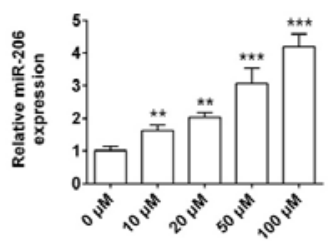

C

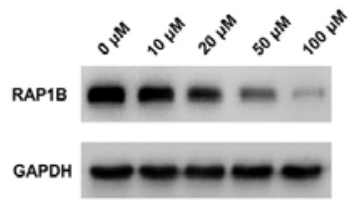

b
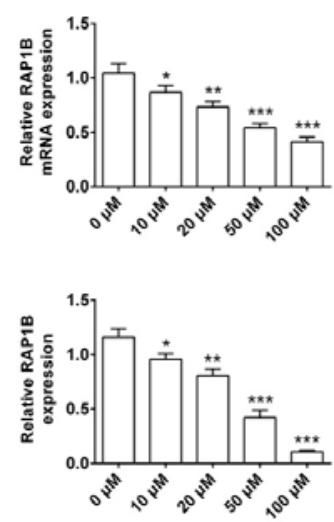

Figure 2: Baicalein upregulates miR-206 expression and reduces RAP1B levels. TPC-1 cells were treated with $10,20,50$, or $100 \mu \mathrm{M}$ baicalein. The expression levels of (A) miR-206 and (B-C) RAP1B were detected by qRT-PCR and western blotting, respectively; ${ }^{*} p<$ $0.05,{ }^{* *} p<0.01,{ }^{* * *} p<0.001$ 


\section{Effect of baicalein on RAP1B level}

The results in Figure $3 \mathrm{~A}$ show that miR-206 overexpression downregulates RAP1B expression, and miR-206 knockdown upregulates RAP1B expression $(p<0.01)$. Moreover, the western blotting data in Figure $3 \mathrm{~B}$ showed that RAP1B expression is upregulated in the baicalein + miR-206 inhibitor group compared with that in the baicalein $+\mathrm{NC}$ inhibitor group $(p<0.01)$. These results suggest that baicalein can regulate miR-206 expression to increase the RAP1B expression level in TPC-1 cells.
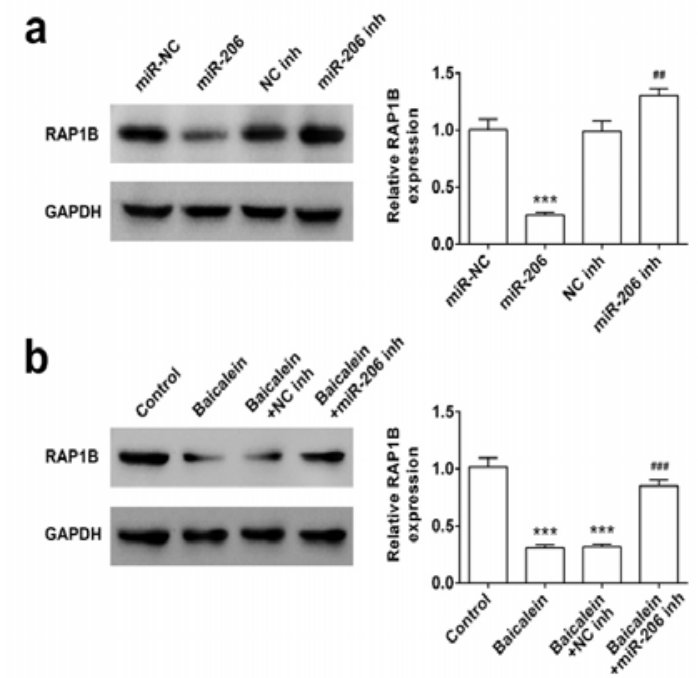

Figure 3: Baicalein reduces RAP1B level by regulating miR-206 expression. TPC-1 cells were treated with $50 \mu \mathrm{M}$ baicalein and transfected with miR206, miR-NC, miR-206 inhibitor, and NC inhibitor. The expression of RAP1B was detected by western blotting. ${ }^{* * *} p<0.001 ;{ }^{\# \#} p<0.001$

Baicalein inhibits cell viability, migration, and invasion by reducing the RAP1B level

RAP1B was transfected into TPC-1 cells to assess the effect of RAP1B on PTC. RAP1B was successfully transfected into TPC-1 cells treated with baicalein (Figure $4 \mathrm{~A} ; p<0.01$ ). Additionally, the MTT assay showed that the cell viability in the baicalein + RAP1B group was more than that in the baicalein + vector group (Figure $4 \mathrm{~B} ; p<$ 0.01 ). Similarly, the Transwell assay showed that the inhibition of cell migration or invasion was alleviated in TPC-1 cells co-treated with baicalein and RAP1B (Figure $4 \mathrm{C} ; p<0.01$ ). The data demonstrated that baicalein affects PTC cell viability, migration, and invasion by regulating RAP1B expression.

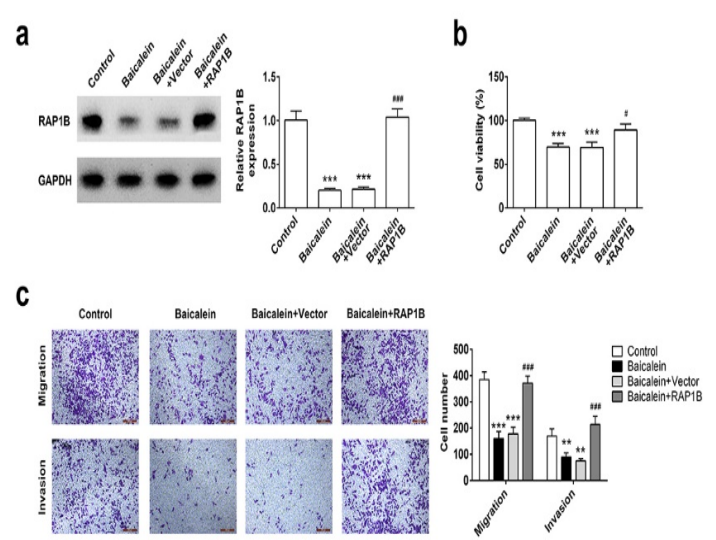

Figure 4: Baicalein inhibits cell viability, migration, and invasion by reducing the RAP1B level. TPC- 1 cells were treated with $50 \mu \mathrm{M}$ baicalein and transfected with RAP1B siRNA and control vector siRNA. (A) The expression RAP1B level was measured by western blotting. (B) Cell viability, (C) migration, and invasion were measured using the MTT and Transwell assays; ${ }^{* *} p<0.01,{ }^{* * *} p<0.001 ;{ }^{\#} p<0.05,{ }^{\# \# \#} p<0.001$

\section{DISCUSSION}

Thyroid cancer is a common endocrine tumor in the human head and neck. The incidence rate of thyroid cancer is increasing rapidly worldwide, with the largest increase in the number of patients diagnosed with PTC [2]. Therefore, presently, more studies are emerging concerning the therapeutic methods, natural medicines, and molecular mechanisms of PTC.

The natural compound baicalein has demonstrated anti-cancer effects [13]. Baicalein inhibits breast cancer cell migration, adhesion, and invasion and induces liver cancer cell apoptosis and autophagy [14,15]. Moreover, baicalein inhibits cell growth in undifferentiated thyroid cancer through the inhibition of ERK and PI3K/AKT pathways and promotion of apoptosis and autophagy [16]. In this study, baicalein inhibited TPC-1 cell growth, indicating that baicalein has an inhibitory effect on PTC.

In recent years, miRNAs have played an important role in tumor differentiation, growth, and apoptosis [9]. miR-206 was found to be abundantly expressed in skeletal muscle, leading researchers to believe for the first time that miR206 is related to cell differentiation [17]. Subsequent studies have shown that miR-206, as a tumor suppressor molecule, is poorly expressed in breast cancer, laryngeal cancer, thyroid cancer, and gastric cancer [12,17-19]. Furthermore, baicalein was found to inhibit cell invasion in osteosarcoma via the miR-183/Ezrin pathway [20]. Hence, this study showed that the 
mechanism of PTC inhibition by baicalein is related to miRNA and its target genes. Baicalein increased miR-206 expression in a concentration-dependent manner, demonstrating that miR-206 is involved in baicalein inhibition of PTC.

RAP1 is a small Ras-like GTPase (SRG), and RAP1B is a subtype of RAP1. The absence of RAP1B leads to impaired angiogenesis, migration of endothelial cells, and the blockade of the MAPK signaling pathway [21]. RAP1B was reported to be upregulated in colorectal cancer tissues and exerts oncogene functions by promoting cell proliferation and metastasis [22]. Similarly, baicalein inhibited RAP1B expression in a concentration-dependent manner, revealing that baicalein has an inhibitory effect on PTC. Additionally, the higher is the concentration of baicalein, the better is the effect. Zhang et al reported that RAP1B is the downstream target gene of miR-518b with a tumor suppressor function [23].

Moreover, a previous study reported a targeting relationship between miR-206 and RAP1B and miR-206 plays a role in inhibiting thyroid cancer by targeting RAP1B [12]. This study confirmed that miR-206 negatively regulates the RAP1B level in PTC cells. Moreover, the baicaleininduced decrease in the RAP1B level was alleviated by miR-206 inhibitor, indicating that miR-206 and RAP1B both play vital roles in the tumor suppressor mechanism of baicalein. We also demonstrated that RAP1B overexpression relieves baicalein-induced inhibition of cell viability, migration, and invasion, indicating that baicalein inhibits PTC cell growth by reducing the RAP1B level.

\section{CONCLUSION}

This study provides evidence that baicalein inhibits cell viability, migration, and invasion via upregulation of miR-206 expression and reduction of RAP1B level in $\mathrm{PTC}$, indicating that baicalein inhibits PTC cell growth by regulating miR-206/RAP1B pathway. This study provides a new drug and molecular target for PTC treatment. However, whether baicalein exerts its cancer-suppressive effects in other ways needs to be investigated more thoroughly.

\section{DECLARATIONS}

\section{Acknowledgement}

The present study was supported by funding from the General Research Projects of Zhejiang
Medical and Health Program (Grant no. 2017196976).

\section{Competing interest}

The authors have no conflicts of interest to disclose.

\section{Contribution of authors}

We declare that this work was performed by the authors named in this article, and all liabilities pertaining to claims related to the content of this article will be borne by the authors. Peng Wang and Jianqiang Zhao designed the study, supervised the data collection, and analyzed the data. Liang Guo interpreted the data and prepared the manuscript for publication. Zhong Liang and Jianlin Lou supervised the data collection, analyzed the data, and reviewed a draft of the manuscript. All the authors read and approved the manuscript.

\section{Open Access}

This is an Open Access article that uses a funding model which does not charge readers or their institutions for access and distributed under the terms of the Creative Commons Attribution License (http://creativecommons.org/licenses/by/ 4.0) and the Budapest Open Access Initiative (http://www.budapestopenaccessinitiative.org/rea d), which permit unrestricted use, distribution, and reproduction in any medium, provided the original work is properly credited.

\section{REFERENCES}

1. Vriens MR, Weng J, Suh I, Huynh N, Guerrero MA, Shen WT, Duh QY, Clark OH, Kebebew E. MicroRNA expression profiling is a potential diagnostic tool for thyroid cancer. Cancer 2012; 118(13): 3426-3432.

2. Maniakas A, Forest V-I, Jozaghi Y, Saliba J, Hier MP, Mlynarek A, Tamilia M, Payne RJJT. Tumor classification in well-differentiated thyroid carcinoma and sentinel lymph node biopsy outcomes: a direct correlation. Thyroid: official journal of the American Thyroid Association 2014; 24(4): 671-674.

3. Vassilopoulou-Sellin R. Low-risk papillary thyroid cancer: treatment options and patient perceptions. Oncology (Williston Park) 2009; 23(7): 589, 592.

4. Zheng F, Wu J, Zhao S, Luo Q, Tang Q, Yang L, Li L, Wu $W$, Hann SS. Baicalein increases the expression and reciprocal interplay of RUNX3 and FOXO3a through crosstalk of AMPKalpha and MEKJERK1/2 signaling pathways in human non-small cell lung cancer cells. J Exp Clin Cancer Res 2015; 34:41. 
5. Cathcart MC, Useckaite Z, Drakeford C, Semik V, Lysaght J, Gately K, O'Byrne KJ, Pidgeon GP. Anticancer effects of baicalein in non-small cell lung cancer in-vitro and in-vivo. BMC Cancer 2016; 16(1): 707.

6. Yan X, Rui X, Zhang K. Baicalein inhibits the invasion of gastric cancer cells by suppressing the activity of the p38 signaling pathway. Oncol Rep 2015; 33(2): 737743.

7. Guo Z, Hu X, Xing Z, Xing R, Lv R, Cheng X, Su J, Zhou $Z, X u Z$, Nilsson $S$ et al. Baicalein inhibits prostate cancer cell growth and metastasis via the caveolin1/AKT/mTOR pathway. Mol Cell Biochem 2015; 406(12): 111-119.

8. Park CH, Han SE, Nam-Goong IS, Kim YI, Kim ES. Combined Effects of Baicalein and Docetaxel on Apoptosis in 8505c Anaplastic Thyroid Cancer Cells via Downregulation of the ERK and Akt/mTOR Pathways. Endocrinol Metab (Seoul) 2018; 33(1): 121-132.

9. Armand-Labit V, Pradines A. Circulating cell-free microRNAs as clinical cancer biomarkers. Biomol Concepts 2017; 8(2): 61-81.

10. Chou CK, Chen RF, Chou FF, Chang HW, Chen YJ, Lee YF, Yang KD, Cheng JT, Huang CC, Liu RT. miR-146b is highly expressed in adult papillary thyroid carcinomas with high risk features including extrathyroidal invasion and the BRAF(V600E) mutation. Thyroid 2010; 20(5): 489-494.

11. Song G, Zhang $Y$, Wang L. MicroRNA-206 targets notch3, activates apoptosis, and inhibits tumor cell migration and focus formation. J Biol Chem 2009; 284(46): 31921-31927.

12. Peng Wang, Jialei Gu, Kejing Wang, Jinbiao Shang, Wang W. miR-206 inhibits thyroid cancer proliferation and invasion by targeting RAP1B. Journal of Cellular Biochemistry 2019; 120(11): 18927-18936.

13. Tang X, Chen J, Yu X, Tang L, Li Y, Xia J. Baicalein and U0126 suppress bladder cancer proliferation via MAPK signaling pathway. Trop J Pharm Res 2017; 16(2): 279286.

14. Shang D, Li Z, Zhu Z, Chen H, Zhao L, Wang X, Chen $Y$. Baicalein suppresses 17- $\beta$-estradiol-induced migration, adhesion and invasion of breast cancer cells via the $G$ protein-coupled receptor 30 signaling pathway. Oncol Rep 2015; 33(4): 2077-2085.

15. Wang Z, Jiang C, Chen W, Zhang G, Luo D, Cao Y, Wu $J$, Ding $Y$, Liu B. Baicalein induces apoptosis and autophagy via endoplasmic reticulum stress in hepatocellular carcinoma cells. Biomed Res Int 2014; 2014: 732516.

16. Pan Y, Yuan F, Li Y, Wang G, Lin Z, Chen L. Bromodomain PHD-finger transcription factor promotes glioma progression and indicates poor prognosis. Oncol Rep 2019; 41(1): 246-256.

17. Kondo N, Toyama $T$, Sugiura $H$, Fujii $Y$, Yamashita $H$. miR-206 Expression is down-regulated in estrogen receptor alpha-positive human breast cancer. Cancer research 2008; 68(13): 5004-5008.

18. Zhang L, Liu X, Jin H, Guo X, Xia L, Chen Z, Bai M, Liu J, Shang $X, W u K$ et al. miR-206 inhibits gastric cancer proliferation in part by repressing cyclinD2. Cancer letters 2013; 332(1): 94-101.

19. Zhang T, Liu M, Wang C, Lin C, Sun Y, Jin D. Downregulation of MiR-206 promotes proliferation and invasion of laryngeal cancer by regulating VEGF expression. Anticancer research 2011; 31(11): 38593863.

20. Zhang J, Yang W, Zhou Y-B, Xiang Y-X, Wang L-S, Hu W-K, Wang $W$-J. Baicalein inhibits osteosarcoma cell proliferation and invasion through the miR-183/Ezrin pathway. Molecular medicine reports 2018; 18(1): 11041112.

21. Chrzanowska-Wodnicka M, Kraus AE, Gale D, White GC, Vansluys J. Defective angiogenesis, endothelial migration, proliferation, and MAPK signaling in Rap1bdeficient mice. Blood 2008; 111(5): 2647-2656.

22. Guo $H, H u X, G e S$, Qian G, Zhang J. Regulation of RAP1B by miR-139 suppresses human colorectal carcinoma cell proliferation. International Journal of Biochemistry \& Cell Biology 2012; 44(9): 1465-1472.

23. Zhang M, Zhou S, Zhang L, Zhang J, Cai H, Zhu J, Huang C, Wang J. miR-518b is down-regulated, and involved in cell proliferation and invasion by targeting Rap1b in esophageal squamous cell carcinoma. FEBS letters 2012; 586(19): 3508-3521. 